\title{
COMPLIMENTS AND REFUSALS IN POLAND AND ENGLAND
}

\author{
JOANNA BHATTI \\ University of Bedfordshire \\ joanna.bhatti@beds.ac.uk \\ VLADIMIR ŽEGARAC \\ University of Bedfordshire \\ vladimir.zegarac@beds.ac.uk
}

\begin{abstract}
There are significant cross-cultural differences in the way compliments and refusals are made and responded to. The investigation of these speech acts touches on some interesting issues for pragmatic theory: the relation between the universal and the culturespecific features of complimenting and refusing, the importance of culture specific strategies in explaining how these speech acts are produced and responded to, as well as the relation between the message conveyed by a compliment or refusal and its affective/emotional effects on the hearer. The pilot study presented in this paper investigates the production and reception of compliments and refusals in the relatively proximate cultures of England and Poland. The findings reveal significant systematic cross-cultural differences relating to refusals, while the differences relating to compliments are fewer and more subtle. The data suggests that the cross-cultural similarities and differences observed can be explained in terms of (a) a universalist view of institutional speech acts and face concerns in rapport management, (b) the Relevancetheoretic view of communication and cognition as oriented towards maximising informativeness and (c) some culture-specific values. These tentative conclusions are based on very limited data and indicate useful directions for future research.
\end{abstract}

\section{Introduction}

The main aim of the pilot study presented in this paper was to collect and analyse data which will inform the design of a larger-scale research project on the cognitive and affective effects of the speech acts of compliment and refusal in the cultures of England and Poland. The article is structured as follows. Section 2 provides the theoretical context for the pilot study and introduces the speech acts of compliment and refusal, focusing on those of their features which have informed our data collection and analysis. This is followed by a description of the study design and methodology in section 3 . Section 4 considers the findings of the study in the context of previous published work on compliments and refusals in Poland and England. The paper concludes with a brief discussion of some implications of our findings for pragmatic theory, and points some promising directions for future research, in section 5 . 


\section{Linguistic politeness and speech acts}

The body of research on linguistic politeness across cultures has been growing steadily over the past few decades. Much of this work focuses on the universality and cultural specificity of speech acts, explores the social implications of performance models, and describes cultural differences in speech act production in terms of interactive strategies (Blum-Kulka, House and Kasper 1989). Our pilot study looks at the similarities and the differences in the ways compliments and refusals are communicated and the affective/emotional responses to these types of speech act, which can be fruitfully described and explained only in the context of some theoretical assumptions of the way people manage rapport in social interaction.

\subsection{Universality and cultural specificity}

Existing models of rapport management have been developed in the study of linguistic politeness within social psychology and pragmatics. This area of research has been dominated by several controversies, including those concerning (a) the relation between the cognitive and the social aspects of linguistically (im)polite behaviour and (b) the extent to which linguistic politeness could be explained in terms of culturally universal concepts (such as Brown and Levinson's (1987) distinction between positive and negative face) in conjunction with a universal model of human communication (such as Grice's (1989) Theory of Conversation). An important question on the cognitive side is whether politeness is communicated. Brown and Levinson's (1987: 4) answer is unequivocal:

On this [Sperber and Wilson's (1986)] view, implicatures about politeness would presumably arise in the same way as all implicatures do, namely, on the assumption that what the speaker said was relevant (maximised information pertinent to context), certain (polite) presumptions would have to be made.

In other words, the comprehension of linguistically polite communicative acts involves deriving implicatures (contextual implications that the communicator evidently intends to convey) about the communicator's 'politeness'. This claim is open to attack from two directions. First, it may seem plausible to argue that polite verbal behaviour does not communicate any 'polite' implicatures in situations where such behaviour is highly expected (and the hearer has no reason to assume that this expectation will not be fulfilled). On Sperber and Wilson's (1986/1995) view, people generally aim to (and are generally presumed to be aiming to) communicate worthwhile information. Therefore, if the speaker confidently expects that the hearer will observe the norms of linguistically polite behaviour, then the fulfilment of this expectation will not provide any new worthwhile information, and no polite implicatures will have been conveyed (see Jary, 1998). Second, even if polite presumptions are implicated, the main social goal of polite linguistic behaviour seems to lie, not with improvements to the hearer's (cognitive) system of beliefs, but with establishing and maintaining a favourable social atmosphere by modifying the affective/emotional disposition of the hearer towards the speaker. In other words, the social function of linguistically polite behaviour may be fulfilled, not 
directly by what the behaviour communicates, but indirectly, by the affective/emotional effects that the communicated information gives rise to (see Žegarac forthcoming). For this reason, we decided to collect cross-linguistic data on the affective/emotional reception of the speech acts of compliment and refusal, as well as on their production. We assumed that particular culture-specific regularities in the production of compliments and refusals would correlate systematically with some culture-specific regularities in the affective emotional responses to these acts.

Brown and Levinson (1987) take a rather strong universalist stance with regard to the basic categories of positive face in explaining politeness. Like speech act theorists, such as Searle (1969), they take the view that the types of indirect speech act relevant to the analysis of linguistic politeness are universal (see Brown and Levinson 1987: 132-142). These authors recognise the existence of culture (and language) specific conventional strategies of polite linguistic behaviour, arguing that 'there can be, and perhaps often are, rational bases for conventions' and that the attested degree of convergence in the forms of polite linguistic behaviour in three unrelated cultures that they have studied could not be explained plausibly without this assumption (Brown and Levinson 1987:59). In contrast to Brown and Levinson, Wierzbicka (1985) argues that the different ways in which linguistic expressions of politeness and their uses in social interaction are (more or less informally) institutionalized cannot be explained in terms of universal categories. She claims that 'specific differences between languages in the area of indirect speech acts are motivated to a considerable degree by differences in cultural norms and cultural assumptions' and that 'the general mechanisms themselves are culture-specific' as evidenced by cross-cultural differences. For example, 'Please' is generally assumed to be the English language equivalent of the Polish expression 'proszę' (which can be glossed as: 'I ask'). This leads Polish speakers of English as a second language to produce utterances such as: 'Please! Sit! Sit!' which are somewhat awkward in English. Wierzbicka concludes that this instance of Polish speakers' evidently non-native communicative behaviour in English cannot be explained by universal features of communication, but by the culture specific 'ubiquitous' use of the Polish performative form 'proszę' ('I ask') in some situations in which 'Please' is not its English equivalent. Wierzbicka also makes the general point that universalist explanations of linguistic politeness, such as the claim that 'politeness is the chief motivation for indirectness' (Ervin-Tripp 1976: 59-61) do not stand up to scrutiny as they make incorrect predictions about the use of indirectness in communication. Thus, if politeness were the reason for communicating indirectly, we would not expect people to make manifestly and intentionally less-than-polite indirect requests, such as 'Will you bloody well hurry up?'. According to Wierzbicka, this shows that the terms communicative 'directness' and 'indirectness' and descriptive comparisons of cultures in terms of their orientation towards the use of (in)directness are 'much too general, much too vague to be really safe in cross-cultural studies, unless the specific nature of a given cultural norm is spelled out.' An example of such a culture-particular norm is the 'Anglo-Saxon principle of noninterference'. She claims that this principle goes a long way towards explaining 'the heavy restrictions on the use of imperatives' (Wierzbicka 1985: 175), but leaves unexplained the comparatively free use of direct personal questions, which needs to be accounted for in terms of another culture-particular norm: the Anglo-Saxon view of information as 'free and public good'. This, Wierzbicka argues, supports the conclusion 
that 'it is very important to try to link language-specific norms of interaction with specific cultural values, such as autonomy of the individual and anti-dogmaticism of Anglo-Saxon cultures or cordiality and warmth of the Polish culture' (Wierzbicka 1985: 176). If polite linguistic behaviour is systematically governed by culture-specific norms such as these, then the cultural differences observed cannot be described as 'accidental' and dismissed from explanatory accounts of human communication, as universalists like Searle (1969) and, presumably, also Brown and Levinson (1987) would have it.

The force of these arguments seems to us to depend on a very specific interpretation of the ideas being criticised. For example, consider Searle's (1969) view that crosscultural and cross-linguistic differences in the use of linguistic indirectness are accidental. On Wierzbicka's interpretation, this claim entails, not only that the principles which govern the use of indirectness are universal, but also that the language particular conventions about the words used are random and are not constrained by culturespecific, possibly also language-specific, rules or strategies about the use of indirectness. However, Searle's view is not at all incompatible with the assumption that the observed regularity in polite linguistic behaviour follows from a culture-particular (possibly also language-particular) norm or strategy. It could be taken to mean simply that the norm or strategy in question is the product of the interaction of various factors at least some of which are a matter of historical accident, so it cannot be explained fully in terms of cultural or cognitive-psychological universals. If this is correct, pragmatics in general, and the study of cross-cultural differences in communication in particular, should focus on uncovering the universal principles of communication as well as the culture and language-specific norms, while accepting that these norms are not fully reducible to universal theoretical concepts and need to be explained by investigating the interplay of universal cognitive-psychological factors and various accidental ecological influences.

The starting theoretical point of our research project is that the Relevance-theoretic turn in post-Gricean pragmatics goes a long way towards addressing the issues that Wierzbicka raises, by explaining communicative behaviour as involving the interaction between a universal generalisation about human communication with various factors, including culture-specific communication strategies. The central claim of Relevance theory is that human cognition and communication are geared towards maximising informativeness while minimising the expenditure of mental processing effort. On this approach, communicative indirectness is explained in terms of maximising the amount of information conveyed, rather than being driven primarily by the interlocutors' orientation towards polite social behaviour. For example, the interrogative utterance 'Will you bloody well hurry up?' communicates both that it is desirable to the speaker that the hearer perform an action (hurry up) and that the hearer give the speaker some information about his intention to perform or not perform this action. If we are right, what seems to have been missing from the universalist approach is a plausible general theory of human communication and cognition, rather than an acknowledgement of the need to take account of culture-specific norms and strategies in explaining politeness phenomena in particular cultures. In this pilot study we begin to explore the possibility that Relevance-theoretic assumptions about human communication are both sufficiently general to provide the basis for explaining the cultural diversity of politeness phenomena and sufficiently constraining to explain the cross-cultural similarities in polite linguistic behaviour. The Relevance-theoretic generalization about the orientation of human 
communication towards maximising informativeness, suggests that relatively small variations in the effort required for representing and mentally processing a communicative act will tend to give rise to relatively large changes in the expected level of informativeness. In other words, Relevance theory predicts that relatively small differences in culture-specific factors which systematically influence communication will also influence the production and the interpretation of particular types of speech act systematically and significantly. When such cultural differences are small, they are likely not to be salient to the members of these proximate cultures and need to be uncovered and described. It seems to us reasonable to expect that empirical research on speech acts such as compliments and refusals, which are found in many cultures, can provide data that corroborates or contradicts this prediction.

\subsection{Compliments}

Compliments can be defined informally as 'both direct and indirect utterances expressing the speaker's positive opinion about the addressee's outward appearance, work, personality traits, possessions, and about third parties closely related to the addressee (e.g. children)' (Jaworski 1995: 64). Holmes gives a similar definition, describing compliments as speech acts that 'attribute to the person addressed some credit for his/her possessions, characteristics, skills, etc., which are positively valued by both interlocutors' (Holmes 1988: 445 in Lubecka 2000: 196). Cheng (2003: 25) observes that 'compliments vary from culture to culture in terms of acceptable or preferred compliment topics, and yet within a culture or speech community, there is a strong agreement as to the relative importance of compliment topics'. The most common topics of compliments are: possessions, appearance, skills and achievements (Holmes 1988; Wolfson 1983).The popularity of these topics varies from culture to culture. According to Herbert (1991) Polish compliments are predominantly related to possession.

Our pilot study aimed to elicit data on compliments about personal possessions and personal appearance, as these are commonly used in England and Poland. Following Lubecka (2000), we adopted Holmes' (1988) distinction between explicit compliments, which 'show openly and in a rather conventional way the compliment giver's affirmative feelings towards the complimentee' and implicit compliments which 'are expressed indirectly, for example by asking for a piece of advice, an opinion, or by thanking or congratulating the interlocutor' (Lubecka 2000: 196). The discourse Completion Task (DCT) scenarios that we used include both compliments which make direct reference to the feature being complimented on and compliments which make indirect reference to the feature being complimented on. However, our DCTs do not include the more context dependent indirect compliments, such as asking for advice, in which it may not be clear whether a compliment is being made at all (e.g. asking for advice on where to go on holiday, which the hearer may or may not be justified to take as a compliment on his knowledge about desirable holiday destinations).

Paying a compliment generally, perhaps always, involves communicating (whether directly or indirectly) a positive evaluative judgement about the hearer (Cheng 1993:59). As people generally find positive evaluations of themselves desirable, compliments are used as 'social lubricants' (Holmes 1988:486) 'to create or maintain rapport' (Wolfson 
1983:86, Manes 1983:97, Herbert 1990:202) by increasing or consolidating 'the solidarity between the speaker and the addressee' (Holmes 1984) and 'to make the hearer feel good by creating a mutual atmosphere of kindness and good will' (Lubecka 2000: 67; Herbert 1989, Manes 1983, Wolfson 1989). Compliments may also straighten or replace other speech acts such as apologies, thanks, or greetings, and may soften criticism or the attitude conveyed by sarcasm. They function as 'ice-breakers' because they can be used aptly to remove the social awkwardness of initiating a conversation (see Wolfson 1983). Complimenting is generally a positive politeness (solidarity) strategy which involves seeking approval and appreciation. However, if they are too personal, compliments may easily threaten the complimentee, who may not be comfortable with the level of intimacy shown by the complimenter (see Spencer- Oatey 2004: 18). The acceptable level of intimacy conveyed by a compliment depends on the relationship, and this was taken account of in our DCTs. We wanted to ensure that the situations in our scenarios are typical in both cultures, so the completion of the task would not depend on contextual assumptions likely to vary vastly among the respondents.

While compliments have social functions, they can also be used to further the speaker's private, personal, goals by manipulating the hearer (say in order to get him to do something that is desirable to the speaker, without taking responsibility for making a request and in this way accepting to be in the hearer's debt). For example, a communicator who says: 'This cake recipe is lovely. I wish I could try it out one day' indirectly communicates her request that the hearer give her the cake recipe, but she may also be hoping that the hearer will offer to make the cake for her or offer to show her how to make the cake (see Herbert 1989, Lewandowska-Tomaszczyk 1989). This and many other similar examples show that there is a fine line between what a compliment communicates indirectly and what is not communicated, but is, rather, a personal, covert, goal that the speaker hopes to achieve by paying the compliment. In fact, a common risk in giving a compliment is that it will be perceived as disingenuous and made with the purpose of influencing the hearer to act in a way which suits the speaker's covert goals.

Compliments may also make the addressee feel uncomfortable by conveying the impression that the person paying the compliment is envious of the person being complimented. A compliment may easily present a threat to the complimentee's negative face. In some cultures (e.g. some East African societies), a compliment about the hearer's personal possessions is standardly interpreted as an expression of the speaker's desire to have the object complimented on and puts the hearer under a social obligation to offer it to the speaker as a gift. This is an extreme case of a culture in which a compliment may make a major imposition on the hearer and, therefore, present a threat to the hearer's negative face. However, the point is quite general: in many cultures in everyday situations the compliment may put the complimentee in a position to put himself out for the complimenter. People are aware that a compliment may be given for a range of overt and covert reasons. The need to minimise the likelihood of the participants' responses to the DCTs being influenced by their uncertainty about the complimenter's motives for giving the compliment or about the way the complimentee would interpret the compliment, was another reason for choosing situational settings in which compliments are commonly given in the respondents' respective cultures.

Compliments can be accepted or rejected, but neither of these responses is risk free. If you accept a compliment, you run the risk of being perceived as lacking modesty and in 
this way damaging your positive face. If you reject a compliment, you run the risk of threatening the complimenter's positive face as well as your own (by showing lack of appreciation for the complimenter's judgement and the complimenter's positive social attitude towards you). Pomerantz (1978) identified the most common strategies in compliment responses: acceptances (agreements), rejections (disagreements), and selfpraise avoidance mechanisms (upgrades and downgrades, referent shifts: return and reassignment). These strategies have been categorised into several groups according to the frequency of their usage. The most common compliment response strategies are: thanking (accepting, expressing gratitude), agreeing (attending to the complimenter's positive face), expressing gratitude, joking (a positive politeness strategy, because it appeals to the solidarity and in-group membership of the interlocutors, although it seems to challenge the compliment), thanking and returning the compliment, encouraging (the complimenter to do or get something as well), offering the object complimented on to the complimenter, explaining, doubting, and rejecting. For the purpose of our study, Pomerantz's (1978) basic three-way categorization of responses to compliments into accepted, returned and rejected was chosen, as it seemed adequate for describing and systematising our data.

\subsection{Refusals}

A refusal is a response to another speech act (an initiating act), such as a request, a suggestion, an offer or an invitation. A refusal communicates that the speaker does not agree to engage in the action proposed by the interlocutor (Chen, Ye and Zhang 1995; Gass and Houck 1999). Therefore, refusals are 'second pair parts' and in face-to-face communication 'they preclude extensive planning on the part of the refuser' (Gass, Houck 1999:2). While compliments may, but need not, threaten the addressee's face, refusals generally tend to be face-threatening, since the possibility of offending an interlocutor through the act of refusing is very high (see Brown and Levinson 1987). Refusals may easily put at risk interpersonal relations between interlocutors. Therefore, they very often require using various strategies for mitigating face-threats, and these strategies are often standardised to varying degrees. Refusing is generally rather complex precisely because it often involves mitigating the face-threat without good opportunities for planning, partly due to lack of time (especially in face-to-face communication) and partly because the request, offer, invitation etc. being refused may be unexpected for the hearer and, in virtue of this, may make it difficult for him to access all the relevant contextual assumptions for deciding whether and how to refuse. Moreover, while it is often appropriate to refuse tactfully, the refusal should, in most situations, not be so indirect as to leave it unclear whether a refusal has been made or not. Consider (1):

(1) A: Would you be able to help me with my homework this evening?

B: Didn't you tell me you'd already done your homework? (example adapted from Gass and Houck 1999: 6)

Depending on the context in which it is interpreted, B's utterance in (1) may, but certainly need not, be taken to implicate (i.e. to communicate indirectly) that $\mathrm{B}$ is 
unwilling to help A with her homework. Thus, if A and B are close friends who regularly help each other with the homework, A may be justified in interpreting B's question as a request for explanation motivated by B's existing belief that A had already completed the homework.

The distinction between direct and indirect refusals is important because refusals are face-threatening acts which need to be mitigated by various politeness strategies, and these strategies generally involve communicative indirectness (Blum-Kulka and Olshtain 1984; Gass and Houck 1999). Direct refusals use performative verbs (e.g. I refuse) or non-performative statements (e.g. No or negative willingness/ability (I can't./I won't./I don't think so). Indirect refusals include statements of regret (I'm sorry.../I feel terrible...), wish (I wish I could help you...), excuse, reason, explanation (My children will be home that night./I have a headache), and proposing alternatives (Beebe, Takakashi and Uliss- Weltz 1990; Blum-Kulka and Olshtain 1984; Ewert and Bromberek-Dyzman 2008). Refusals are responses to other speech acts: requests, invitations, offers and suggestions. These four speech acts which may 'trigger' acceptance or refusal have been called 'initiating acts' (Gass and Houck 1999). The function of various strategies for refusing is to reassure the hearer that he is still approved of and in this way mitigate the threat to the hearer's positive face. Apart from giving a 'good enough' reason for refusing, the speaker may use various negotiation strategies aimed at minimising the risk of causing offence, such as offering an alternative.

Direct and indirect refusal strategies require the knowledge of complex, often culture-specific, norms of social interaction. Formulaic expressions for expressing refusals directly can be divided into performative (e.g. 'I refuse') and non-performative (e.g. 'No/ I can't'). The most common indirect refusal strategies include: avoidance, offering an alternative, postponement, putting blame on a third party or something which you don't have control over, being silent, hesitating, showing lack of enthusiasm (Rubin 1983:12-13), expressing regret, offering excuse/reason/explanation, alternative, presenting self-defence, and agreeing (Ewert and Bromberek-Dyzman 2007). The list is not exhaustive and there may well be some overlap between the strategies.

\section{The study}

Two groups of participants (one Polish and one English) were asked to respond to a number of Discourse Completion Tasks about some everyday social situations which involved complimenting, refusing and responding to compliments and refusals. The study was open to both genders and anonymous. The only personal details the participants were asked to give were: age, gender and occupation. The age range was 18 to 29 (and was not restricted by the researchers). There were 30 participants in each group (most of them students or professionals): 22 female and 8 male respondents aged 19 to 29 , in the Polish group, and 15 male and 15 female respondents aged 18 to 29, in the English group.

The main aims of the pilot study were: to collect data which might shed light on the differences and similarities in the production and reception of the speech acts of compliment and refusal in England and Poland, to explore the relation between the 
production of these speech acts and affective/emotional responses to them, and to consider the implications of the findings for a larger-scale project on the role of emotions in intercultural communication.

The research instrument was a series of discourse completion tasks (DCTs) which included four scenarios inviting informants to give a compliment (scenario (a)), make a refusal (scenario (b)), respond to a compliment (scenario (c)) and respond to a refusal (scenario (d)). Each scenario included equal status participants (low power-distance): friends, relatives, neighbours. The DCTs were written as role plays with different but common social situations inviting the use of casual conversational language in completing the task. Each task was followed by a question about the participant's immediate emotional response to complimenting, refusing, responding to the compliment and responding to the refusal. The English and Polish versions of the DCTs are as similar as two documents written in different languages can be.

Although DCTs may not be fully reliable research instruments, as they do not necessarily reflect accurately people's behaviour in, and their perceptions of, naturally occurring conversations, this data collection method affords researchers the opportunity to collect typical responses relating to examples of typical situations from members of particular cultural groups, enabling them to categorize responses in a way which shows how representative these responses are of a particular culture. Another advantage of DCTs is that they make possible the collection of large amounts of data over short time spans. Responses can be compared in relation to a number of variables (e.g. age, gender, culture). Finally, DCTs have been used very successfully in many cross-cultural studies (see Blum-Kulka 1982, Olshtain 1983; Olshtain, Cohen 1983; Blum-Kulka, House, Kasper 1989; Beebe, Takahashi, Uliss-Weltz 1990; Gass and Neu 1996), so a great deal of information about the design and the use of DCTs is readily available.

\section{Findings}

The most interesting findings of our study are that Polish participants' responses to refusals were more negative and the refusals they made were more elaborate than those of English participants. The data on compliments shows a great degree of similarity, but also some subtle differences which seem worth investigating further.

\subsection{Compliments}

For scenario (a), where participants are asked to give a compliment on their brother's/sister's haircut, we looked for compliments which make direct reference to the object of complimenting and those in which the object of complimenting is referred to indirectly (table 1). For scenario (c), where participants are asked to respond to a compliment on their coat, compliments we categorised into accepted, rejected and returned (table 2). For both scenarios ((a) and (c)) participants' responses about their emotions associated with giving and receiving a compliment have been divided into positive (e.g. 'happy', 'fine', 'good' or 'ok'), negative (e.g. 'sad', 'disappointed') and 
neutral (e.g. 'normal', 'natural', 'not bothered by the situation'). The numerical data on these situations is given in tables 1 and 2 .

\begin{tabular}{|c|c|c|c|}
\hline \multicolumn{2}{|c|}{ COMPLIMENTS } & \multicolumn{2}{c|}{$\begin{array}{c}\text { GIVING A COMPLIMENT } \\
\text { (haircut) }\end{array}$} \\
\cline { 3 - 4 } & ENG & PL \\
\hline \multirow{3}{*}{ TYPES } & $\begin{array}{c}\text { direct reference to compliment } \\
\text { object }\end{array}$ & 28 & 23 \\
\cline { 2 - 4 } & $\begin{array}{c}\text { indirect reference to } \\
\text { compliment object }\end{array}$ & $\underline{2}$ & $\underline{7}$ \\
\hline \multirow{2}{*}{$\begin{array}{c}\text { EMOTIONAL } \\
\text { RESPONSES }\end{array}$} & positive & $\mathbf{2 2}$ & $\mathbf{2 1}$ \\
\cline { 2 - 4 } & negative & $\mathbf{0}$ & $\mathbf{1}$ \\
\cline { 2 - 4 } & neutral & $\mathbf{8}$ & $\mathbf{8}$ \\
\hline
\end{tabular}

Table 1. Compliments (types and responses): Giving a compliment

Polish and English respondents gave comparable responses with a strong preference for direct reference to compliment object (ENG 29, PL 23). Emotional responses were also similar in both groups. Emotional experience was evaluated positively by the majority of respondents, with only 1 Polish participant reporting a negative emotional experience while giving a compliment. The most striking difference in Table 1 is that more Polish respondents, (7), than English, (2), gave compliments with indirect reference to the compliment object, which seems interesting, as indirectness in communication is generally considered a feature of English culture. A study involving greater numbers of respondents and other speech acts which are often performed with varying degrees of indirectness could establish more conclusively how significant this finding is and how this difference should be explained.

The two groups' responses to compliments (Table 2) are almost identical, the only difference being that 2 English respondents reported a negative emotional experience when responding to a compliment, in contrast to 0 Polish respondents.

\begin{tabular}{|c|c|c|c|}
\hline \multirow{2}{*}{ COMPLIMENTS } & \multicolumn{2}{c|}{ RESPONDING TO A COMPLIMENT (Coat) } \\
\cline { 3 - 4 } & & ENG & PL \\
\hline \multirow{3}{*}{ TYPES } & accepted & 29 & 29 \\
\cline { 2 - 4 } & rejected & 0 & 0 \\
\cline { 2 - 4 } & returned & 1 & 1 \\
\hline \multirow{3}{*}{ EMOTIONAL RESPONSES } & positive & 27 & 28 \\
\cline { 2 - 4 } & negative & 2 & 0 \\
\cline { 2 - 4 } & neutral & 1 & 2 \\
\hline
\end{tabular}

Table 2. Compliments (types and responses): Responding to a compliment

There were no rejected compliments in either group. However, some differences emerge when a distinction is made between directly accepted compliments (e.g. 'thank you'- the use of performative verb) and indirectly accepted compliments (e.g. 'I like it, too'):

- $\quad$ Compliments accepted directly: ENG 29 and PL 26.

- $\quad$ Compliments accepted indirectly: ENG 0 and PL 3 
A larger study is needed to check whether the 3 indirect acceptances of the compliment reflect a relatively significant cultural preference in Poland for accepting compliments indirectly. The similarity in the two groups' responses to compliments are probably due to the convention in both cultures that 'thank you' (English)/ 'dziękuję' (Polish) is the most appropriate response to a compliment (Herbert 1990:207, Herbert 1989:5). This convention is found in many cultures, which is not surprising. By accepting the compliment directly, the speaker attends to the hearer's positive face (appreciation for the hearer's positive social attitude towards the speaker) and maintains her own positive face (by showing that she values the hearer's perception of her as an appreciative person). The assumption that people in all cultures generally have a strong preference for being approved of, and the further assumption that by accepting a compliment directly the speaker attends to the hearer's positive face as well as maintaining her own, lead to the conclusion that we should expect to find across cultures a strong preference for accepting compliments with gratitude (unless this is precluded by some other cultural norm). The strategy of accepting a compliment indirectly (e.g. 'I like it too') is risky because the complimentee's appreciation of the compliment may not be conveyed if the complimenter fails to figure out the complimentee's indirectly communicated appreciation of the compliment. It may well be the case that the success of indirect acceptance of compliments depends to a greater extent on paralinguistic factors than that of direct acceptance. Clearly, it would be interesting to investigate further the role of prosody and body language in the production of direct and indirect responses to compliments within and across cultures.

Another risk involved in indirectly accepting the compliment (e.g. by saying 'I like it too'), and often also in accepting the compliment directly, is that the speaker may lose positive face by showing lack of modesty. Cultures differ in the extent to which communicating positive self-evaluative judgements is socially acceptable. By accepting the compliment, the complimentee also implicitly accepts a positive evaluation of himself, which, depending on particular cultural values and norms, may be seen as undesirable and, therefore, damaging to the complimentee's positive face. The following example of compliment acceptance by an English respondent shows that when accepting compliments directly by expressing gratitude people sometimes take the trouble to cancel or moderate the positive self-evaluation that the expression of gratitude might convey. In our example, the English respondent expressed gratitude for the compliment by saying: 'why, thank you!'. As it is evident to the complimentee (and in the corresponding real-life situation it would be evident to both complmenter and complimentee), that the question word 'why', is not intended to be relevant here as a request for information about the complimenter's reasons for giving the compliment, but rather, because it implicates that the complimentee does not think of his coat as worthy of a compliment and shows modesty. In this usage, 'why' functions rather like an exclamative interjection which expresses the speaker's attitude of surprise towards the compliment. Of course, this interpretation depends largely on the prosodic pattern of 'Why, thank you' in speech. It seems worth noting here that 'Why' is followed by a comma. This is (almost certainly) intended to mark it off as an intonational unit, which lends support to our conclusion that 'Why' is used here as a discourse marker showing surprise and leading to implicatures about the speaker's modesty, not as a request for information. 
There were no striking differences between the English and the Polish respondents' descriptions of their emotional reactions to giving a compliment and receiving a compliment, as shown in Tables 3 and 4.

\section{Typical compliments and responses to compliments. ENG compliments}

1. Typical words used to:

a) make a compliment (haircut):

Direct reference to object: 'Nice haircut.', 'Hair looks good.'

- Indirect reference to object: 'You look nice'

b) respond to a compliment (coat):

- Accepted: 'Thanks', 'Cheers'

- Rejected: No responses

- Returned: "Ah, thanks Mary. Yours is too.'
2. Typical emotional responses:

a) After making a compliment (haircut)

- Positive: 'Fine', 'Happy', 'Felt good'

- Negative: None

- Neutral: 'Normal', 'No problem'

b) After responding to a compliment (coat)

- Positive: 'Very nice to be complimented', 'Happy', 'Confirmation of a good purchase'

- Negative: ' $50 \%$ irritated, $50 \%$ complimented', 'Embarrassed but happy.'

- Neutral: 'ok, didn't bother me much'

Table 3. Typical compliments and responses to compliments (English respondents)

\begin{tabular}{|c|c|}
\hline \multicolumn{2}{|c|}{ Typical compliments and responses to compliments. (Polish respondents) } \\
\hline $\begin{array}{l}\text { 1. Typical words used: } \\
\text { a) To make a compliment (haircut): } \\
\text { - Direct reference to the object: } \\
\text { 'Nice haircut, you look great (it } \\
\text { really suits you).', 'cool haircut', } \\
\text { 'Great haircut!' } \\
\text { - Indirect reference to the object: } \\
\text { 'you look great, what a change', } \\
\text { 'you look awful' [ironical], 'What } \\
\text { a cutie!' } \\
\text { b) To respond to a compliment (coat): } \\
\text { Accepted: 'Thanks, that's my } \\
\text { latest purchase!', 'Thanks! I'm } \\
\text { crazy about coats!', 'I like it too' } \\
\text { - Rejected: None } \\
\text { - Returned: 'Thank you, you look } \\
\text { great too'. }\end{array}$ & $\begin{array}{l}\text { 2. Typical emotional responses: } \\
\text { a) After making a compliment (haircut) } \\
\text { - Positive: 'Fine', 'Happy', 'Felt good' } \\
\text { - Negative: 'amused' } \\
\text { - Neutral: 'Normal', 'I hoped that I was } \\
\text { pleasing her.', 'That was a natural } \\
\text { response for me.' } \\
\text { b) After responding to a compliment (coat) } \\
\text { - Positive: 'I was very happy that also } \\
\text { other people like my new coat. My } \\
\text { friend's compliment cheered me up.', } \\
\text { 'Very nice', 'I'm glad that my choice has } \\
\text { been commented on!' } \\
\text { - Negative: None } \\
\text { - Neutral: 'nice and weird', 'Generally } \\
\text { good but I don't want to talk anymore } \\
\text { about how great I look in a new coat so } \\
\text { probably I'm changing a topic' }\end{array}$ \\
\hline
\end{tabular}

Table 4. Typical compliments and responses to compliments. (Polish respondents)

The data relating to refusals (Tables 5 and 6) shows more cross-cultural differences. For scenario (b) (birthday invitation), where respondents were asked to make a refusal, responses were categorised as direct or indirect. In scenario (d), where respondents are asked to respond to a refusal, responses were categorised as favourable (i.e. positive: 
giving consent, understanding) and unfavourable (i.e. negative: disapproval, disappointment).

\begin{tabular}{|c|c|c|c|}
\hline \multirow{2}{*}{\multicolumn{2}{|c|}{ REFUSALS }} & \multicolumn{2}{|c|}{ REFUSING (Birthday Party) } \\
\hline & & ENG & PL \\
\hline \multirow[t]{2}{*}{ TYPES } & direct & $\mathbf{3}$ & $\mathbf{0}$ \\
\hline & indirect & 28 & 30 \\
\hline \multirow[t]{3}{*}{ RESPONSES } & positive & $\underline{10}$ & $\underline{\mathbf{0}}$ \\
\hline & negative & 15 & 23 \\
\hline & neutral & 5 & 7 \\
\hline
\end{tabular}

Figure 5. Refusals (types and responses): making a refusal.

Indirect refusals to a birthday party invitation were found to be strongly favoured in both cultures, with only 3 English respondents refusing directly. Even in the three direct refusals the event to which the speaker has been invited is not mentioned explicitly:

(2) I can't come [to your birthday party] I'm sorry',

(3) I can't [come to your birthday party] my cousin's wedding is on the same day.

We will catch up next time. Have a good one.

(4) I'm afraid I won't be able to make it [to your birthday party].

We consider the refusals (2) to (4) direct because in each instance the negation is explicit and the linguistic form of the utterance specifies an ellipsed constituent (given in square brackets). This constituent is easily accessible in the immediate context of the hearer, so it need not be realised phonetically (although it is part of the descriptive, i.e. truthconditional, content of the utterance). Refusals categorised as indirect do not contain explicit negation, and were categorised as indirect on that basis (regardless of whether or not they have ellipsed constituents):

(5) I am really sorry [because I can't come to your birthday party], Paul. I'm going to my cousin's wedding that day.

(6) I would love to but I have a family celebration on the same day. (Polish)

Clearly, (5) and (6) communicate refusal more indirectly than (2) to (4) because in (5) negation is not explicit and the refusal ('because I can't come to your birthday party') needs to be supplied from the context. In (6) 'but' introduces an utterance which contradicts a salient contextual assumption. In this instance, this contextual assumption, based on the general knowledge that a person who 'would love to' go to a friend's birthday party, will do so, is roughly: 'The speaker will attend the birthday party'. The utterance introduced by 'but' is optimally relevant when interpreted as denying this contextual assumption ('I have a family celebration on the same day') and the refusal is communicated indirectly.

A more detailed pragmatic analysis of (in)directness in communicating refusals could be given. However, our main aim here is to draw attention to subtle, possibly culturespecific, differences in the degree of (in)directness in making refusals between two relatively proximate cultures. It is not particularly surprising that indirect refusals are strongly favoured in both cultures. Acceptance is manifestly the preferred response to a social invitation, because refusals threaten the hearer's positive face. A speaker who is favourably socially disposed towards the hearer will want to avoid threatening the hearer's positive face (and in this way to maintain her own). 
There were no positive emotional responses to making refusals among Polish respondents. Most were upset about refusing (23), while 7 respondents' affective response was neutral (e.g. they reported not feeling either bad or happy; refusing was just something they had to do as family is more important to them; they knew or assumed the person who had invited them would understand; they felt that the reason they had given was genuine and sincere, rather than a mere excuse, so they did not need to feel sorry about refusing). In completing this DCT scenario none of the Polish respondents reported positive emotions. However, 10 out of 30 English respondents described their emotional response to making a refusal in positive terms. They thought they had a valid reason for not attending the barbecue party and felt this made them feel alright about making the refusal. English respondents also gave fewer negative emotional responses to refusing than Polish respondents. Among English respondents 1 direct response was related to a positive emotional response and 1 to a neutral emotional response. This means that a direct response to a refusal did not trigger negative emotional responses in this group. Table 6 presents the data for scenario (d), where informants were asked to respond to a refusal to their barbecue invitation. The data shows some noticeable differences between Polish and English responses.

\begin{tabular}{|c|c|c|c|}
\hline \multirow{2}{*}{\multicolumn{2}{|c|}{ REFUSALS }} & \multicolumn{2}{|c|}{$\begin{array}{l}\text { RESPONDING TO A REFUSAL } \\
\text { (Barbecue) }\end{array}$} \\
\hline & & ENG & $\mathbf{P L}$ \\
\hline \multirow{2}{*}{ TYPES } & favourable & 21 & 14 \\
\hline & unfavourable & 9 & 16 \\
\hline \multirow{3}{*}{ RESPONSES } & positive & 15 & 6 \\
\hline & negative & 6 & $\overline{18}$ \\
\hline & neutral & 9 & 6 \\
\hline
\end{tabular}

Table 6. Refusals (types and responses): responding to a refusal.

A significant majority of English informants (21) responded to the refusal favourably. Only 9 respondents gave unfavourable responses. Polish informants' responses were very evenly balanced (14 favourable and 16 unfavourable responses). In other words, fewer English (6) than Polish (18) informants made unfavourable responses to the refusal and more English (15) than Polish (6) respondents gave favourable responses. So, the highest number of emotional responses in the English group were positive, (15), while the highest number of emotional responses in the Polish group were negative, (16). There is a tendency among Polish informants to be more apologetic while making a refusal than merely giving a reason for refusing, which English respondents would consider a 'good enough' response (see Tables 7 and 8).

Typical responses to refusals and responding to refusals. (English respondents)

\section{Typical words used to:}

a) make a refusal (birthday party):

- Direct: 'I can't come m8 sorry', 'I can't my cousins wedding is on the same day. We will catch up next time
2. Typical emotional responses:

a) After making a refusal (birthday party)

- Positive: 'alright, I just couldn't make it, didn't do it on purpose'

- Negative: 'Not too good; I hate doing 
Typical responses to refusals and responding to refusals. (English respondents)

Have a good one'

'I'm afraid I won't be able to make it.'

- Indirect:' I am really sorry, Paul. I'm going to my cousin's wedding that day'

b) respond to a refusal (barbecue):

- Favourable: 'that's alright, give me a shout when you're back', 'That's fine, no worries. I hope you have a nice time.'

- Unfavourable: 'That's a shame, maybe another time. Have a great time on your holiday!' things like that', 'feel bad'

- Neutral: 'it's one of those things, I'm sure he will understand, cousins wedding is a one off'

b) After responding to a refusal (barbecue)

- Positive: 'Ok. if he can't make it he can't make. That's fine'

- Negative: 'His problem. Maybe he'll miss out on something'

- Neutral: 'Not that bothered, because I see John everyday as a neighbour, I suppose I feel different if it's someone I have not seen in a long time.'

Table 7. Typical responses (English respondents)

\begin{tabular}{|c|c|}
\hline \multicolumn{2}{|c|}{ Typical refusals and responses to refusals. (Polish respondents) } \\
\hline $\begin{array}{l}\text { 1. Typical words used: } \\
\text { a) To make a refusal (birthday } \\
\text { party): } \\
\text { - Direct: None } \\
\text { - Indirect: 'I would love to but I } \\
\text { have a family celebration on the } \\
\text { same day' } \\
\text { b) To respond to a refusal } \\
\text { (barbecue): } \\
\text { - Favourable: 'ok. Maybe next } \\
\text { time then.' } \\
\text { - Unfavourable: 'Shame, Your } \\
\text { loss (-)' }\end{array}$ & $\begin{array}{l}\text { 2. Typical emotional responses: } \\
\text { a) After making a refusal (birthday party) } \\
\text { - Positive: None } \\
\text { - Negative: 'awful', 'I'm upset to refuse the } \\
\text { invitation.' } \\
\text { - Neutral: 'Neutral. I would love to go to your } \\
\text { party but I had to choose, my brother is closer } \\
\text { to me' } \\
\text { b) After responding to a refusal (barbecue) } \\
\text { - Positive: 'I understand that he could have } \\
\text { different plans and couldn't come to the } \\
\text { barbeque. I didn't feel offended by his refusal } \\
\text { to my invitation' } \\
\text { - Negative: 'I was upset and it was difficult for } \\
\text { me' } \\
\text { - Neutral: 'Normal' }\end{array}$ \\
\hline
\end{tabular}

Table 8. Typical refusals and responses to refusals (Polish respondents)

Polish respondents sometimes offer several alternatives, as if wanting to make sure that they are not offending or hurting their interlocutor (see examples of typical refusals in Figure 8). Some Polish participants made rather long and rather apologetic refusals, emphasising the speaker's regret about having to refuse (e.g. 'Paul, I haven't seen you for so long and we are lacking time for a chat and now it turned out that my cousin's wedding is on the same day as your party... I'm terribly sorry but I have to reject your invitation. If I could, I would double myself, you know that, but cousin's wedding, you know, pressure from the family, besides all of us waiting for a long time now for them to 
formalize their relationship, they make such a beautiful couple and I don't see my cousin too often. I promise that you will get a gift in advance and I will do whatever I can to visit you and say happy birthday in person. Please don't get upset/ angry, we will catch up!'). Polish respondents' descriptions of their emotional responses to refusals were also longer and more descriptive than those of English respondents' who tended to be more straightforward and less apologetic. They typically apologised for refusing. Some, but not all, English participants also gave reasons for refusing (e.g. 'Erm. I am afraid I can't make it. My cousin's wedding is on the same day '). So, English participants thought that giving a conventional apology, possibly also a rational explanation for their decision, was an adequate justification for refusing, while Polish participants seemed more concerned about the emotional impact of the refusal on the interlocutor.

\section{Concluding remarks}

The small scale study presented in this paper shows that there are significant similarities in the production and reception of compliments and refusals in the cultures of Poland and England. As these two cultures are relatively proximate, this finding is not surprising.

The differences between compliments in Poland and England are less well evidenced in our data and are rather more subtle than the differences in the production and reception of refusals. The data on both types of speech act presented in this paper lead to some tentative conclusions which call for further research.

More Polish respondents, (7), than English, (2), gave compliments with indirect reference to the compliment object, which seems interesting, as indirectness in communication is generally considered a feature of the English culture. Typical compliments given by Polish respondents suggest that a person's possessions are worth complimenting on only provided it is evident to both complimenter and complimentee that the object being complimented on is a major change to the complimentee's usual appearance. If this were not the case, 'you look great, what a change', would be a somewhat insulting compliment on a coat, as it would be taken to imply something disparaging about the hearer's appearance previous to getting a new coat. This would also explain the greater number of indirect compliments. If the object complimented on marks a striking (i.e. mutually evident) change to the complimentee's usual appearance or circumstances, it can be interpreted easily even if it is rather indirect. Thus, 'What a cutie!' is appropriate as a compliment on the way the complimentee's wearing a new coat only provided the complimentee can figure out easily enough that it is the new coat that makes the difference between her usual appearance and her appearance in this situation.

The differences in refusing and responding to refusals in our study are more striking, and, perhaps, more interesting. As pointed out in section 2, a prediction which follows from the Relevance-theoretic approach to communication is that relatively small variations in the cultural context can lead to relatively significant differences in the interpretation and the production of communicative acts. It seems to us that the differences between the two cultural groups of respondents who took part in our study are consistent with this prediction and, therefore, support it. The differences relating to 
refusals are systematic, and we can reasonably reliably assume that they reflect some cultural differences between Poland and England. However, it is not entirely clear what these cultural differences are due to. Judging by our respondents' comments on how refusing and receiving a refusal made them feel, Polish culture seems to place a rather high value on others' needs and wants (in the types of everyday situations described in our DCT scenarios). It seems that in Poland acting in a way which is desirable to others in these types of situation has a comparatively higher weight than in England, where an expression of regret and giving a rational justification for refusing is adequate. Polish respondents' emotional reactions to refusals and their verbal responses to refusals did not provide evidence that they followed conventional culture-specific strategies. Their responses were similar in the comparatively high level of concern for the affective emotional impact of refusing on the hearer, and can be explained in general pragmatic terms, without positing special strategies for refusing. English respondents' refusals seemed to follow a more conventional pattern. This is what we would expect to observe if English culture does not put a high value on the hearer's needs and wants in relation to the speaker's.

The ways in which a type of speech act is performed is more likely to be standardised (i.e. to be produced by following strategies and formulas) if the speech act is not expected to be very informative. For this reason, formulaic expressions do not give rise to expectations of a high level of informativeness and hearers allocate comparatively little mental effort to interpreting them. In the DCT settings in our study, refusals seem to be more informative (technically, more relevant) in the Polish culture than in the English culture. Our best explanation for this is that the complexity of the justifications for refusing by Polish participants reflects the presumed comparatively high relevance of this speech act to the hearer. While the emotions associated with refusing and the linguistic realisations of refusals and responses to refusals seem to us to support this conclusion, further research is needed.

\section{References}

Beebe, Leslie, Tomoko Takahashi, and Robin Ullis-Weltz. 1990. "Pragmatic transfer in ESL refusals". In: Robin C. Scarcella (ed.) Developing communicative competence in a second language, pp. 55-73. New York: Newbury House.

Blum-Kulka, Shoshana. 1982. "Learning to say what you mean in a second language: A study of the speech act performance of learners of Hebrew as a second language." Applied Linguistics 13 (2), 29-59.

Blum-Kulka, Shoshana, Juliane House and Gabriele Kasper. 1989. "Investigating crosscultural pragmatics: An introductory overview". In: Shoshana Blum-Kulka, Juliane House and Gabriele Kasper (eds). Cross-Cultural Pragmatics: Requests and Apologies. Norwood, NJ: Ablex, 1-34.

Blum-Kulka, Shoshana, \& Elite Olshtain. 1984. "Requests and apologies: A crosscultural study of speech act realization patterns CCSARP”. Applied Linguistics, 5, 196-213. 
Beebe, Leslie, Tomoko Takahashi, and Robin Uliss-Weltz. 1990. "Pragmatic transfer in ESL refusals". In Developing Communicative Competence in a Second Language, R. Scarcella, E.S. Andersen and S.D. Krashen (eds), 55-73, New York: Newbury House.

Brown, Penelope and Stephen C. Levinson. 1987.. Politeness. Some universals in language usage. Cambridge: Cambridge University Press.

Chen, Xia, Lei Ye, and Yanyin Zhang. 1995. "Refusing in Chinese" in Kasper, G. (ed.), Pragmatics of Chinese as native and target language. Hawai'i: University of Hawai'i. pp. 119-163.

Cheng, Winnie. 2003. Intercultural Conversation. Amsterdam, Philadelphia: John Benjamins Publishing Company.

Ervin-Trip, Susan. 1976. "Is Sybil there? The structure of some American English directives?" Language in Society 5: 25- 66.

Ewert, Anna, Katarzyna Bromberek-Dyzman. 2007. "Declining offers: L2 users' pragmalinguistic choices in L1".In: Cap, P. - J. Nijakowska (eds) Current trends in pragmatics, Newcastle: Cambridge Scholars Publishing, 378-409.

Ewert, Anna, and Katarzyna Bromberek-Dyzman. 2008. "Impossible requests: L2 users' pragmalinguistic choices in L1 acts of refusal". In: Roberts, L., F. Myles, and A. David (eds) EUROSLA Yearbook 8. Amsterdam/Philadelphia: John Benjamins, 3251.

Gass, Susan M. And Joyce Neu (eds.). 1996. Speech Acts Across Cultures. Challenges to Communication in a Second Language. Berlin, New York: Mouton de Gruyter.

Gass, Susan M. and Noel Houck. 1999. Interlanguage Refusals: A Cross-cultural Study of Japanese- English. Berlin: Mounton.

Grice, Herbert Paul. 1989. Studies in the Way of Words. Cambridge, MA: Harvard University Press.

Herbert, Robert K.. 1989. "The ethnography of English compliments and compliment responses: a contrastive sketch". In Wieslaw Oleksy (ed.) Contrastive Pragmatics, Amsterdam: Benjamins, 3-35.

Herbert, Robert K.. 1990. "Sex-based differences in compliment behaviour". Language in Society 19: 201-224.

Herbert, Robert K.. 1991. "The sociology of compliment work: An ethnocontrastive study of Polish and English". Multilingua 10 (4): 381-402.

Holmes, Janet. 1988. "Paying compliments. A sex-preferential politeness strategy."

Journal of Pragmatics 12: 445-465.

Jary, Mark. 1998. "Relevance Theory and the communication of politeness. " Journal of Pragmatics. 30: 1-9.

Jaworski, Adam. 1995. “"This is not an empty compliment': Polish compliments and the expression of solidarity”. International Journal of Applied Linguistics 5.1, 63-94.

Lewandowska-Tomaszczyk, Barbara. 1989. Praising and complimenting, In Wieslaw Oleksy (ed.) Contrastive Pragmatics, Amsterdam: John Benjamins, 73-100.

Lubecka, Anna. 2000. Requests, Invitations, Apologies and Compliments in American English and Polish. A Cross-cultural Communication Perspective. Krakow: Ksiegarnia Akademicka. 
Manes, Joan. 1983. "Compliments: a mirror of cultural values". In Nessa Wolfson and Elliot Judd (eds) Sociolinguistics and Language Acquisition (96-102). Rowley, MA: Newbury House.

Olshtain, Elite. 1983. "Sociocultural competence and language transfer: The Case of Apology". In Susan M. Gass and Larry Selinker (eds) Language Transfer in Language Learning Rowley, MA: Newbury House, 232-249.

Pomerantz, Anita M.. 1978. "Compliment responses: notes on the co-operation of multiple constraints." In Jim Schenkein (ed.) Studies in the Organization of Conversational Interaction. New York: Academic press, 79-112.

Rubin, Joan. 1983. "How to tell when someone is saying 'No' revisited". In Nessa Wolfson and Elliot Judd (eds) Sociolinguistics and Language Acquisition (10-17). Rowley, MA : Newbury House.

Searle, John R.. 1969. Speech Acts: An essay in the philosophy of language. Cambridge: Cambridge University Press.

Spencer-Oatey, Helen (ed.). 2000. Culturally Speaking. Managing Rapport through Talk across Cultures. London: Continuum.

Sperber, Dan and Deirdre Wilson. 1986; [2nd edition with postface] 1995. Relevance: Communication and Cognition. Oxford: Blackwell.

Wierzbicka, Anna. 1985. "Different cultures, different languages, different speech acts: Polish vs. English". Journal of Pragmatics 9, 145-178.

Wolfson, Nessa. 1983. "An empirically based analysis of complimenting in American English". In Nessa Wolfson and Elliot Judd (eds) Sociolinguistics and Language Acquisition (82-95). Rowley, MA : Newbury House.

Wolfson, Nessa. 1989. Perspectives: Sociolinguistics and TESOL. Rowley, MA: Newbury House.

Žegarac, Vladimir, (forthcoming) Emotions, Communication and Relevance.

\begin{abstract}
About the Authors
Joanna Bhatti is currently working on a project on the communication of emotions in England and Poland at the University of Bedfordshire. She holds the MA in Intercultural Communication and the BA in English Language Studies from University of Bedfordshire, as well as the BA in English Studies (English Philology) from WSJO (College of Modern Language Studies), Poznan, Poland.
\end{abstract}

Vladimir Žegarac after obtaining a $\mathrm{PhD}$ in Linguistics from University College London (UCL) worked as a researcher in the Survey of English Usage (UCL) and at Middlesex University. Since 1995 he has been employed at the University of Bedfordshire where he is currently a Reader in Language and Communication. In recent years, the specific topics he has looked at include the implications of Relevance theory for the study of intercultural communication, lexical meaning, second language learning, ideology in newspaper language. 